\title{
Kinematics of swimming in two burrowing anguilliform fishes
}

A. Herrel ${ }^{1,2}$, H. F. Choi ${ }^{3}$, N. De Schepper ${ }^{3}$, P. Aerts ${ }^{2}$ and D. Adriaens ${ }^{3}$

1. Département d'Ecologie et de Gestion de la Biodiversité, Muséum National d’Histoire Naturelle, 57 rue Cuvier, Case postale 55, 75231, Paris Cedex 5, France.

2. Department of Biology, University of Antwerp, Universiteitsplein 1, B-2610 Antwerpen, Belgium.

3. Department of Biology, Ghent University (U.G.), K.L. Ledeganckstraat 35, B-9000 Gent, Belgium.

\# pages: 17

\# tables: 2

\# figures: 4

\section{Address for correspondence:}

Anthony Herrel

Dépt. d'Ecologie et de Gestion de la Biodiversité

Muséum National d’Histoire Naturelle

57 rue Cuvier, CP 55

phone : $++33-140798120$

75231, Paris

Fax : ++33-140793773

France

e-mail: anthony.herrel@mnhn.fr 


\begin{abstract}
Anguilliform or eel-like fishes are typically bottom dwellers, some of which are specialized burrowers. Although specializations for burrowing are predicted to affect the kinematics of swimming, it remains unknown to what extent this is actually the case. Here we examine swimming kinematics and efficiency of two burrowing anguilliform species, Pisodonophis boro and Heteroconger hassi with different degrees of specialization for burrowing. Our data suggest that differences in the swimming kinematics may indeed be related to the difference in burrowing specialization and style between both species. The resemblance between the swimming kinematics of $P$. boro and previously published data for Anguilla anguilla and Anguilla rostrata may be linked with the relatively limited burrowing specialization of $P$. boro and suggests an overall stereotypy in anguilliform forward swimming patterns. The body of $H$. hassi, in contrast, is more specialized for tail-first burrowing and backward swimming bears a striking resemblance to the backward burrowing motions observed in this species. These motions differ significantly from backward swimming in Anguilla and those in P. boro. The kinematics of forward swimming are, however, comparable across species. Thus, our data suggest that specializations for burrowing may affect swimming kinematics in anguilliform fishes but also suggest that forward swimming and burrowing are not necessarily incompatible. Future studies comparing the kinematics and mechanics of burrowing in these and other anguilliform fish are needed to better understand how specializations for burrowing constrain backward swimming in H. hassi.
\end{abstract}




\section{Introduction}

Anguilliform or eel-like fishes are characterized by an elongated and flexible body and swim using backward moving waves of lateral body undulations. Their body shape seems particularly well suited for swimming through narrow passages in a complexly structured environment, rather than for a pelagic continuous swimming life style (Nelson, 1994). Yet, extreme cases of horizontal and vertical sustained pelagic swimming are known for migratory species such as Anguilla anguilla or A. rostrata (Aarestrup et al., 2009). Some anguilliform species have adopted a burrowing life style involving different levels of specialization. Although little is known about burrowing in anguilliform fish in general, anecdotal observations suggest that these animals burrow by means of lateral undulations of the body, even in pelagic species like Anguilla japonica (Aoyama et al., 2005). Yet, species differ in whether they burrow head or tail first and this has consequences for their morphology. For example tail-first burrowers have a more rigid distal tail segment allowing them to penetrate the substrate tail-first (De Schepper et al. 2007a,b). An increased strengthening of intervertebral connections along the caudal region could also benefit burrowing, but may also, in turn, affect the flexibility of the tail, and consequently the kinematics of swimming. Previous studies on anguilliform swimming have been limited to two closely related and morphologically similar species: Anguilla anguilla (European eel) and Anguilla rostrata (American eel). Although often considered good models for anguilliform fish (Smith, 1989a), both the European and American eel are unusual as they undertake migrations to the Sargasso Sea involving continuous locomotion over thousands of kilometers without feeding (van Ginneken et al., 2005). In contrast, most tropical eel species migrate over much shorter distances to spawn (Aoyama et al., 2003). Given the presumably strong selection on efficient swimming and the deep sea origin (Inoue et al., 2010) of both Anguilla-species, these animals may potentially not be the most representative models for locomotion in anguilliform fishes in general.

In the present study, we provide a kinematic description of swimming in two burrowing anguilliform fishes with a different degree of burrowing specialization: Pisodonophis boro (Ophichthidae) and Heteroconger hassi (Congridae) (Smith, 1989a,b; De Schepper et al 2007a,b). The former species is a less specialized burrower, which burrows both head- and tailfirst. The latter species is a specialized tail-first burrower. In the present paper we quantify the 
kinematics of forward swimming in both species and additionally provide base-line data on backward swimming. To test whether a burrowing life-style affects the kinematics and efficiency of swimming, we compare the swimming kinematics across species, and to previously published data for migratory anguillids. We predict that the more specialized $H$. hassi will be more divergent in its swimming kinematics from A. anguilla and A. rostrata than the more generalized P. boro. Given the specialized tail morphology including a stiffening of the posterior-most segment (De Schepper et al., 2007b) we predict lower tail undulation amplitudes in H. hassi. Additionally, we predict that the tail-first burrowing $H$. hassi will be more constrained in its backwards swimming movements (i.e. more stereotyped movement pattern) than in its forward swimming given its specialized burrowing behavior (Tyler and Smith, 1992).

\section{Materials and methods}

\section{Study animals}

The fishes used in this study were obtained through the commercial trade. The $P$. boro eels were maintained at $25^{\circ} \mathrm{C}$ in a freshwater aquarium, the bottom of which was covered with gravel. Heteroconger hassi is a marine species and individuals were maintained in an aquarium with artificial salt water (salinity $=24 \%$, temperature $=25^{\circ} \mathrm{C}$ ), the bottom of which was covered with a $25 \mathrm{~cm}$ layer of sand. For the acquisition of the kinematic data, three individuals of $P$. boro and two individuals of $H$. hassi were used. The P. boro individuals had a standard length of 17.0, 17.4 and $21.7 \mathrm{~cm}$; the H. hassi individuals 23.2 and $27.4 \mathrm{~cm}$.

\section{Video recordings}

The swimming motions of the eels were filmed using a digital high speed camera (Redlake, MotionPro) at $250 \mathrm{~Hz}$. Two aquaria with bases of $15 \times 180 \mathrm{~cm}$ and $40 \times 120 \mathrm{~cm}$ were used for filming. Because the eels usually swam at the bottom, the aquaria were filled with $10 \mathrm{~cm}$ of water only, and swimming was filmed in dorsal view. For some sequences a funnel was placed in the tank to induce the animals to swim straight and in the middle of the aquarium. Swimming motions were only considered from the moment the fish had left the funnel completely. Although

this method worked well to induce forward swimming, it was unsuccessful in inducing backward swimming. A first set of video sequences was recorded for all three $P$. boro individuals while 
swimming freely in the aquarium; a second set of recordings including $H$. hassi as well the largest $P$. boro specimen were recorded using the setup with funnel.

\section{Kinematic analysis}

Only sequences in which the eels were swimming straight, continuous (i.e. not accelerating or decelerating) and which included at least one tail beat cycle were retained for analysis. This resulted in a total of 22 forward (5, 3 and 14 for each individual) and 5 backward ( 3 and 2) sequences for $P$. boro and 8 forward ( 4 for each individual) and 8 backward sequences (one individual only) for $H$. hassi. The swimming motions in the video sequences were analyzed throughout one cycle of the trailing edge (tail or snout tip, forward and backward swimming respectively). Each AVI-sequence was first down sampled to obtain about twenty frames per cycle that were subsequently saved as a JPEG-sequence. In each image the body midline was quantified by manually digitizing a set of twenty (P. boro) or thirty (H.hassi) points on the midline of the fish using Didge (version 2.2.0, Alistair Cullum, Department of Biology, Creighton University, Omaha, NE). After digitization, the coordinates of these points were exported to Excel and raw data files were subsequently processed with custom routines written in MATLAB 6.0 (The Mathworks Inc.).

The amplitude of the lateral body undulations was calculated for 11 equally spaced points along the body midline, the first and the last of which were the snout point and the tail tip, respectively. These points are further referred to as 'body points'. The positions of these body points were calculated from the manually digitized coordinate sequences in the raw data files by means of a two dimensional cubic spline interpolation algorithm. The direction of motion was determined by performing a bi-variate linear regression (Sokal \& Rohlf, 1998) on all the digitized midlines in a sequence. By applying a rotational coordinate transformation, the body midlines were rotated until the direction of motion coincided with the horizontal (x) axis so that the vertical (y) coordinate of each body point equaled the distance of the lateral excursion of that point. The undulation amplitude in each body point was calculated as half the lateral distance covered between both extremes of the lateral excursions in a cycle. The wave period of the lateral undulations was determined as twice the time between the two extreme lateral positions. The undulation wave length was calculated as twice the mean distance between the body midline 
points in which the direction of motion was crossed and the wave speed as the wave length divided by the wave period.

An alternative method was developed to determine the lateral undulation amplitudes during backward swimming in H. hassi (Fig. 2). Because the motions were not rectilinear, no unique direction of motion could be determined. The lateral undulation in the body points was therefore measured relative to the inflection points of the body midline. In each frame of a sequence, the inflection points were determined as points of zero curvature, calculated using the following equation (Weisstein, 2006):

$$
\kappa=\frac{x^{\prime}(t) y^{\prime \prime}(t)-x^{\prime \prime}(t) y^{\prime}(t)}{\left(x^{\prime}(t)^{2}+y^{\prime}(t)^{2}\right)^{3 / 2}}=\frac{1}{R(x, y)},
$$

with $\mathrm{x}(\mathrm{t})$ and $\mathrm{y}(\mathrm{t})$ representing the parametric coordinate functions describing the body midline in the two dimensional plane and $\mathrm{R}(\mathrm{x}, \mathrm{y})$ the radius of curvature. The derivatives were calculated based on the positions of 51 equally spaced midline points. The wave-like nature of the lateral undulations implies a similar behavior for the body curvature, which means that the curvature in each body point also varies periodically. Because the body midlines were not perfectly smooth, resulting in a noisy time profile of the body curvature, midlines were smoothed using a fourthorder zero-phase-shift Butterworth low-pass filter (Winter, 1990). The digitization also resulted in the occurrence of unwanted inflection points, which were eliminated by performing a five point Savitchky-Golay-smoothing on the midline. The lateral excursion distance of each body point was then given by the vertical coordinate after rotating the body midline until the line through the two adjacent inflection points coincided with the horizontal axis. The undulation amplitudes were calculated as the sum of the two extreme lateral excursion distances in an undulation cycle divided by two. It should be noted that the undulation amplitude cannot always be found for all the body points using this alternative method because these points are not always flanked by two inflection points. The undulation wave period was obtained by considering the undulation time profiles of as many body points as possible. In each body point a wave period was calculated as outlined above. Because of the lack of a unique direction of motion, the wave 
length was determined as the average distance between the inflection points in the body midlines. Division of the wave length by the wave period gave the wave velocity. As results obtained using both methods give generally similar results for forward swimming (slopes; frequency $=0.92$; wave length $=1.08$; wave speed $=0.99$ ) we feel confident that this method also gives a reasonable approximation of the kinematics of backward swimming in $H$. hassi.

In both the rectilinear and the alternative method, the swimming speed was obtained through quantification of the path of the center of mass. Because the individuals of both species had a fairly homogeneous body width (Fig. 1), the mass was considered to be evenly distributed along the body. The position of the center of mass in each frame was therefore calculated by averaging the spatial coordinates of 51 equally spaced midline points. The distance covered by the center of mass was then plotted as a function of time and the average speed was calculated as the slope of the linear regression forced through the origin. In the rectilinear sequences it was found that the path of the center of mass undulated laterally relative to the direction of motion. In these cases, the projected distance along the direction of motion was considered instead of the total path length of the center of mass. The stride length was calculated as the swimming speed multiplied by the undulation period.

To estimate the propulsive or Froude efficiency of swimming, the elongated body theorem (EBT) of Lighthill (1960; 1970) was used. In this theorem, the efficiency is approximated as:

$\eta=\frac{V+U}{2 V}$

with $\mathrm{V}$ and $\mathrm{U}$ equal to the undulation wave speed and the swimming speed, respectively. This equation is commonly used because of its simplicity and the possibility to calculate the efficiency from kinematic parameters alone. The propeller efficiency (or slip factor), which is given by U/V, was also calculated as an alternative measure of the propulsive efficiency.

\section{Statistical analyses}


To compare the results between the two species and between the different locomotion modes, two-tailed t-tests were used. Relations between different kinematic parameters were examined by means of linear regressions. All statistical analyses were performed in Statistica 6.0 (Statsoft Inc.).

\section{Results}

Kinematics of swimming

As illustrated in figure 1, forward swimming in both species is characterized by lateral body undulations with amplitudes increasing from snout to tail tip (P. boro: $\mathrm{r}^{2}=0.99 ; P<0.001 ; H$. hassi: $\mathrm{r}^{2}=0.83 ; P=0.002$ ). This increase is less constant for $H$. hassi, which has an amplitude profile that levels off in the tail region (body position 0.7-0.9 in Fig. 2) before increasing further toward the tail tip. The undulation amplitudes are not significantly correlated with the position along the body and are more or less evenly distributed during backward swimming in both species, with the amplitudes being notably small in $H$. hassi for this swimming mode. The curvature amplitudes display a similar increase along the body ( $P$. boro: $\mathrm{r}^{2}=0.99 ; P<0.001 ; H$. hassi: $\mathrm{r}^{2}=0.50 ; P=0.03$ ), and this increase is again less constant in $H$. hassi. No significant correlation exists between the curvature amplitude and the position along the body for backward swimming in $P$. boro. The amplitude of curvature is, however, correlated with body position during backward swimming in $H$. hassi $\left(\mathrm{r}^{2}=0.69 ; P=0.006\right)$, with the curvature amplitude being smaller in the anterior region than in the posterior region of the body. The curvature amplitudes are also noticeably higher during backward swimming compared to forward swimming in both species.

\section{Speed effects}

A summary of the swimming kinematics for both species and both forward and backward swimming is provided in table 1 . The effect of swimming speed on the kinematics of swimming is summarized in table 2 . Whereas the undulation wave frequency shows a clear correlation $\left(\mathrm{r}^{2}\right.$ $=0.82$ ) with the specific swimming speed (Fig. 3 , Table 2) this is not the case for backward swimming in $P$. boro. Note, however, that sample sizes for backward swimming are small and thus additional data are needed to rigorously test this finding. In all cases, however, frequency increases with increasing swimming speed. In $P$. boro the undulation frequency is greater during 
backward swimming compared to forward swimming, but shows a similar increase with swimming speed as observed during forward swimming. The same pattern is observed for $H$. hassi, but in this species the slope of the regression of wave frequency on swimming speed is significantly greater during backward swimming than during forward swimming (Fig. 3A). Moreover, the slope during backward swimming is higher for $H$. hassi compared to $P$. boro (Fig. 3A) implying that $H$. hassi has to undulate its body at a higher frequency than $P$. boro to attain similar swimming speeds. Other kinematic parameters were weakly or not correlated with swimming speed (Table 2). The Froude efficiency increases with swimming speed during forward swimming in P. boro (Fig 3B, Table 2).

\section{Differences between forward and backward swimming}

For both species, forward and backward swimming differ significantly in the specific amplitude (i.e. expressed in body lengths) and wave length of the undulations as well as in the specific stride length (all $P<0.001$ ). The average specific undulation amplitude along the body during backward swimming is smaller than the specific amplitude during forward swimming (Table 1). This difference is small in P. boro (about 30\%) but rather large in $H$. hassi (about 70\%). The specific undulation wave length and the specific stride length are smaller during backward than during forward swimming (Table 1). The difference in the specific wave length between both types of locomotion is again smaller for $P$. boro (about 25\%) than for $H$. hassi (about 50\%) while the difference in the specific stride length is comparable between species (40-50\%).

\section{Interspecific differences}

The specific tail tip amplitude during forward swimming is smaller in $H$. hassi compared to $P$. boro $(P=0.01)$. The average specific undulation amplitude along the body during backward swimming in $P$. boro is also larger than that observed for $H$. hassi $(P<0.001)$. The specific undulation wave length is also smaller in $H$. hassi than in $P$. boro (all $P<0.001$ ) and this difference is larger for backward swimming (about 50\%) than for forward swimming (about $30 \%$ ). The same pattern holds for the specific stride length (forward: $P=0.02$; backward $P=$ 0.005), with a difference of about $25 \%$ for forward and about $40 \%$ for backward swimming.

\section{Discussion}




\section{Comparative swimming kinematics}

Forward swimming in both $P$. boro and $H$. hassi follows the same general trends observed for other fish using undulatory swimming modes (Alexander, 2003), with the undulation amplitude increasing from the snout towards the tail tip during forward swimming. The undulation frequency is correlated with the specific swimming speed while the tail tip amplitude, undulation wave length and stride length are not. The undulation frequency increases with increasing swimming speed, indicating that higher swimming speeds are achieved by a faster tail beat rather than by increasing the tail beat amplitude, which is also commonly observed in other anguilliform fishes (e.g. Gillis, 1998; D’Aout and Aerts, 1999; Muller et al., 2001; Tytell, 2004; Tytell and Lauder 2004). In addition, the mean values of the kinematic parameters during forward swimming obtained in the present study for $P$. boro are comparable to those reported for A. anguilla and A. rostrata in previous studies (Gillis, 1998; D’Aout and Aerts, 1999). In the specialized burrower, $H$. hassi, these values are less similar to those of both Anguilla species with regard to forward swimming. The undulation frequency of $H$. hassi increases faster with increasing swimming speed, which implies that this species uses faster body undulations to attain the same swimming speed. Although the specific tail tip amplitudes are comparable, the specific undulation wave length of $H$. hassi is smaller. This means that more undulations are present along the body of this species during forward swimming compared to the two Anguilla-species and $P$. boro. Consequently, more body segments are used to generate thrust. This does, however, not result in an increase of the specific stride length, which is smaller than that observed in the other three species.

A strong similarity also exists for the backward swimming kinematics of P. boro and A. anguilla. As observed by D’Août and Aerts (1999) for A. anguilla, the specific undulation amplitude increases in the anterior body region during backward swimming, resulting in a more homogenous amplitude distribution along the body with average amplitude values close to those of the tail tip amplitude during forward swimming. The specific undulation wave length and specific stride length are also smaller during backward swimming. Given the similarity in backward swimming between $P$. boro and A. anguilla, backward swimming in $H$. hassi seems to be kinematically divergent. Although the amplitudes of the body undulations are also evenly distributed along the body in backward swimming in $H$. hassi, they are substantially smaller than 
during forward swimming and occur in a higher number. Moreover, a much higher undulation frequency is observed at high backward swimming speeds compared to A. anguilla and P. boro, and the difference in the increase of the undulation frequency with increasing swimming speed between forward and backward swimming is also much larger (Fig. 3A).

The differences in the swimming kinematics between $P$. boro and $H$. hassi may be related to their different level of burrowing specialization, morphology and ecology. Pisodonophis boro burrows both head- and tail-first and can be regarded as a less specialized burrower. The head and tail tip of this species are characterized by a robust skeletal structure (Tilak and Kanji, 1968; De Schepper et al., 2007a), which has been interpreted as an adaptation for penetration of the sediment. The trunk, however, does not seem to display far-reaching burrowing adaptations and the external morphology is very similar to that of non burrowing eels. As $P$. boro is an active open water hunter, similar to the two Anguilla-species (Smith, 1989a) it may be constrained in the development of burrowing specializations that would affect its swimming efficiency. The ecology of $H$. hassi on the other hand, is very different. This species lives in self-constructed, vertically oriented tunnels that are rarely abandoned (Bauchot and Bassot, 1863). Moreover, $H$. hassi feeds on plankton carried along by the currents (Smith, 1989b). The specialization for this semi-sedentary burrowing life style seems to have been accompanied by a modification of the body shape in this species (De Schepper et al., 2007b). The body of H. hassi is not characterized by a posterior decrease in body width as is observed in P. boro and the two Anguilla species. The width remains uniform along most of the body, which only tapers in a small region near the tail tip. The body is in addition very cylindrical and has a width of only $1.5 \%$ of the body length, giving $H$. hassi a very elongated appearance (see Fig. 1). In addition, the caudal skeleton in $H$. hassi is highly reduced and strengthened, and the intrinsic caudal musculature is also reduced (De Schepper et al., 2007b).

This considerable difference in body morphology is, however, not reflected in the forward swimming kinematics of $H$. hassi. Only minor differences such as the less constant posterior increase of the undulation amplitude and the smaller specific wave length are noticeable. Although forward swimming in anguilliform fish thus appears to be rather stereotyped, further data from additional species are needed to test the generality of this observation. Contrary to 
forward swimming, backward swimming in $H$. hassi appears to be divergent but this difference is likely also not directly related to the differences in tail morphology between species as tail amplitudes are high in $H$. hassi. However, the undulation pattern during backward swimming strongly resembles that of the tail-first burrowing motion (Tyler and Smith, 1992) suggesting that these animals may be constrained in the types of movements they are able to perform during backward swimming. Indeed, synthetic resin casts of the burrows of $H$. hassi show that the burrows are characterized by a wavy shape, reflecting the body undulations during burrowing. Moreover, the burrow of $H$. hassi is characterized by a wave form with a specific amplitude and wave length which are respectively 2 and 21\% of the body length, values very similar to those reported here for backward swimming in $H$. hassi. The typical anguilliform pattern of backward swimming has apparently been lost in this species, potentially related to its behavioral specialization for tail-first burrowing. If the ability to rapidly move backwards into a burrow is selected for, the motor pattern needed to do so may be hard-wired and consequently these animals may be unable to change motor and movement patterns during backwards movements. Given that data on backward swimming in $H$. hassi were derived from a single individual data on the kinematics and mechanics of swimming and burrowing in additional individuals of this species are needed. This would allow us to test the generality of our results, and to better understand the constraints associated with this behavior.

\section{Comparison of the swimming efficiency}

The swimming efficiencies for forward swimming calculated in the present study for $P$. boro and $H$. hassi are relatively high and comparable to the efficiencies reported for A. anguilla and A. rostrata (Table 1). This is certainly remarkable for $H$. hassi, given its semi-sedentary burrowing life style. Although the calculated Froude efficiency does not allow for a conclusive comparison between P. boro, H. hassi and the two Anguilla-species, the undulation frequency and the specific stride length can be used as rough indicators. This suggests that Heteroconger hassi is less efficient at backward swimming as a higher undulation frequency is needed to attain the same swimming speed (Fig. 3). This implies that the muscles contract at a higher frequency, likely resulting in a higher metabolic energy consumption. The smaller specific stride length of $H$. hassi can also be interpreted as an indication of reduced swimming efficiency (Videler and Wardle, 1991). 


\section{Conclusions}

The data gathered in the present study indicate some differences in swimming kinematics of burrowing anguilliform fishes, which may be related to their burrowing life style and behavioral specialization. Yet, the similarity in swimming kinematics between $P$. boro and non-burrowing eels such as $A$. anguilla and $A$. rostrata illustrates that undulatory swimming and burrowing are not necessarily incompatible. This similarity also indicates that the kinematic data derived from studies of both Anguilla-species can indeed be generalized to anguilliform fishes in general. However, as illustrated by $H$. hassi, deviations from this general pattern do occur and may be related to specializations for burrowing.

\section{Acknowledgements}

Funded by a research program of the fund for scientific research - Flanders (FWO-Vl G.0388.00).

\section{References}

Aarestrup, K., Okland, F., Hansen, M.M., Righton, D., Gargan, P., Castonguay, M., Bernatchez, L., Howey, P., Sparholt, H., Pedersen, M.I., McKinley, R.S., 2009. Oceanic spawning migration of the European eel (Anguilla anguilla). Science 325, 1660-1660.

Alexander, R.McN., 2003. Principles of Animal Locomotion. Princeton University Press, Princeton.

Aoyama, J., Wouthuyzen, S., Miller, M.J., Inagaki, T., Tsukamoto, K., 2003. Short-distance spawning migration of tropical fresh water eels. Biol. Bull. 204, 104-108.

Aoyama, J., Shinoda, A., Sasai, S., Miller, M.J., Tsukamoto, K., 2005. First observations of the burrows of Anguilla japonica. J. Fish Biol. 67, 1534-1543. 
Bauchot, M.-L., Bassot J.-M., 1958. Sur Heteroconger longissimus Günther (Téléostéen anguilliforme) et quelques aspects de sa biologie. Bull. Mus. Natl. Hist. Nat., 2e Sér. 30, 258261.

D’Août, K., Aerts, P., 1999. A kinematic comparison of forward and backward swimming in the eel Anguilla anguilla. J. Exp. Biol. 202, 1511-1521.

De Schepper, N., De Kegel, B., Adriaens, D., 2007a. Pisodonophis boro (Ophichthidae: Anguilliformes): specialization for head-first and tail-first burrowing? J. Morphol. 268, 112-126.

De Schepper, N., De Kegel, B., Adriaens, D., 2007b. Morphological specializations in heterocongrinae (Anguilliformes: Congridae) related to burrowing and feeding. J. Morphol. 268, 343-356.

Gillis, G.B., 1998. Environmental effects on undulatory locomotion in the American eel Anguilla rostrata: kinematics in water and on land. J. Exp. Biol. 201, 949-961.

Inoue, J.G., Miya, M., Miller, M.J., Sado, T., Hanel, R., Hatooka, K., Aoyama, J., Minegishi, Y., Nishida, M., Tsukamoto, K., 2010. Deep-ocean origin of the freshwater eels. Biology Letters 6, 363-366.

Lighthill, M.J., 1960. Note on the swimming of slender fish. J. Fluid Mech. 9, 305-317.

Lighthill, M.J., 1970. Aquatic animal propulsion of high hydromechanical efficiency. J. of Fluid Mech. 44, 265-301.

Müller, U.K., Smit, J., Stamhuis, E.J., Videler J.J., 2001. How the body contributes to the wake in undulatory fish swimming: flow fields of a swimming eel (Anguilla anguilla). J. Exp. Biol. 204, 2751-2762.

Nelson, J.S., 1994. Fishes of the World (third edition). Wiley \& Sons, New York. 
Smith, D.G., 1989a. Family Anguillidae. In: Böhlke, B. (Ed.), Fishes of the Western North Atlantic. Part 9, vol. 1. Orders Anguilliformes and Saccopharyngiformes. Sears Foundation for Marine Research, New Haven, pp. 25-47.

Smith, D.G., 1989b. Family Congridae. In: Böhlke, B. (Ed.), Fishes of the Western North Atlantic. Part 9, vol. 1. Orders Anguilliformes and Saccopharyngiformes, Sears Foundation for Marine Research, New Haven, pp. 460-567.

Sokal, R.R., Rohlf, F.J., 1998. Biometry (third edition). W. H. Freeman \& Company, New York.

Tilak, R., Kanji, S.K., 1968. Studies on the osteology of Pisodonophis boro (Hamilton). Gegenbaurs Morphol. Jahrb. 113-114, 501-523.

Triantafyllou, G.S., Triantafyllou, M.S., Grosenbauch, M.A., 1993. Optimal thrust development in oscillating foils with application to fish propulsion. J. Fluids Struct. 7, 205-224.

Tyler, J.C., Smith, C.L., 1992. Systematic significance of the burrow form of seven species of Garden eels (Congridae: Heterocongrinae). American Mus. Novitates 3037, 1-13.

Tytell, E.D., Lauder, G.V., 2004. The hydrodynamics of eel swimming. I. Wake structure. J. Exp. Biol. 207, 1825-1841.

Tytell, E.D., 2004. The hydrodynamics of eel swimming. II. Effect of swimming speed. J. Exp. Biol. 207, 3265-3279.

van Ginneken, V., Antonissen, E., Müller, U.K., Booms, R., Eding, E., Verreth, J., van den Thillart, G., 2005. Eel migration to the Sargasso: remarkably high swimming efficiency and low energy costs. J. Exp. Biol. 208, 1329-1335. 
Videler, J.J., Wardle, C.S. 1991. Fish swimming stride by stride: speed limits and endurance.

Rev. Fish. Biol. Fish. 1, 23-40.

Weisstein, E.W., 2006. Curvature. In MathWorld, a Wolfram Web Resource, http://mathworld.wolfram.com/Curvature.html.

Winter, D., 1990. Biomechanics and Motor Control of Human Movement (second edition). Wiley \& Sons, New York.

\section{Figure legends}

Figure 1: Images from video recordings illustrating swimming in the different species studied. a) forward swimming in $P$. boro, b) backward swimming in $P$. boro, c) forward swimming in $H$. hassi, d) backward swimming in H. hassi. Arrows indicate the direction of movement. Note the high frequency and low amplitude of the undulatory waves in $H$. hassi during backward swimming.

Figure 2: a) illustration of the alternative method used to determine the lateral undulation amplitudes during backward swimming in H. hassi. Because the motions were not rectilinear, no unique direction of motion could be determined. The lateral undulation in the body points was therefore measured relative to the inflection points of the body midline. Squares represent equally spaced body points; the grey circles indicate inflection points. The body midline has been rotated such that the line intersecting the first two inflection points lies parallel with the $\mathrm{x}$-axis. The undulation amplitude of a given body point is determined as the perpendicular distance between the line intersecting two consecutive inflection points and the body point. Dashed lines indicate the lines interconnecting subsequent inflection points. b) graph illustrating the correlation between the wave frequency calculated using the rectilinear method and the alternative method described higher for swimming in $H$. hassi. Although both methods give similar results, the alternative method slightly underestimates the true undulation frequency (slope $=0.92$ ).

Figure 3: Figure illustrating the mean undulation amplitudes of the different body points in both species during forward and backward swimming. Vertical bars indicate standard errors of the 
mean. The position along the body is indicated relatively to the snout tip, which has a body position equal to zero. Note how in both species the undulation amplitude increases from head to tail during forward swimming. During backward swimming the undulation amplitude is relatively uniform across the entire length of the body in both species. Note that no amplitudes could be calculated for backward swimming in $H$. hassi as amplitudes were calculated using the curvature method due to the non-linear backward swimming motions. Open circles: $H$. hassi forward swimming; closed circles: P. boro forward swimming; open diamonds: H. hassi backward swimming; closed diamonds: $P$. boro backward swimming.

Figure 4: Plots of the linear regressions of two kinematic parameters; a) wave frequency and b) Froude efficiency in function of swimming speed. Regression coefficients are listed in table 2. Open circles: $H$. hassi forward swimming; closed circles: $P$. boro forward swimming; open diamonds: $H$. hassi backward swimming; closed diamonds: $P$. boro backward swimming. 
Table 1: Summary of swimming kinematics during forward and backward swimming in P. boro and H. hassi.

\begin{tabular}{|c|c|c|c|c|c|c|c|c|}
\hline & \multicolumn{4}{|c|}{ P. boro } & \multicolumn{4}{|c|}{ H. hassi } \\
\hline & \multicolumn{2}{|c|}{ forward } & \multicolumn{2}{|c|}{ backward } & \multicolumn{2}{|c|}{ forward } & \multicolumn{2}{|c|}{ backward } \\
\hline & mean & S.E. & mean & S.E. & mean & S.E. & mean & S.E. \\
\hline $\begin{array}{l}\text { specific und. } \\
\text { amplitude (L) }\end{array}$ & 0.11 & 0.0036 & 0.076 & 0.0025 & 0.087 & 0.0058 & 0.025 & 0.0019 \\
\hline $\begin{array}{l}\text { und. } \\
\text { amplitude (m) }\end{array}$ & 0.025 & 0.0012 & 0.014 & 0.001 & 0.022 & 0.0013 & 0.0058 & 0.0004 \\
\hline $\begin{array}{l}\text { specific wave } \\
\text { length (L) }\end{array}$ & 0.63 & 0.0083 & 0.47 & 0.021 & 0.46 & 0.014 & 0.23 & 0.0048 \\
\hline $\begin{array}{l}\text { wave length } \\
\text { (m) }\end{array}$ & 0.14 & 0.0047 & 0.084 & 0.0037 & 0.12 & 0.0041 & 0.054 & 0.0011 \\
\hline $\begin{array}{l}\text { wave frequency } \\
(\mathrm{Hz})\end{array}$ & 1.80 & 0.11 & 3.75 & 0.59 & 1.37 & 0.21 & 5.32 & 0.94 \\
\hline $\begin{array}{l}\text { specific wave } \\
\text { speed (L/s) }\end{array}$ & 1.15 & 0.082 & 1.74 & 0.28 & 0.62 & 0.087 & 1.23 & 0.20 \\
\hline $\begin{array}{l}\text { wave } \\
\text { speed }(\mathrm{m} / \mathrm{s})\end{array}$ & 0.25 & 0.011 & 0.31 & 0.051 & 0.16 & 0.019 & 0.29 & 0.047 \\
\hline $\begin{array}{l}\text { specific swim } \\
\text { speed (L/s) }\end{array}$ & 0.72 & 0.057 & 1.01 & 0.27 & 0.41 & 0.063 & 0.79 & 0.13 \\
\hline $\begin{array}{l}\text { swim } \\
\text { speed }(\mathrm{m} / \mathrm{s})\end{array}$ & 0.15 & 0.0096 & 0.18 & 0.045 & 0.10 & 0.014 & 0.18 & 0.03 \\
\hline $\begin{array}{l}\text { specific stride } \\
\text { length }(\mathrm{L})\end{array}$ & 0.39 & 0.016 & 0.26 & 0.034 & 0.29 & 0.015 & 0.15 & 0.01 \\
\hline $\begin{array}{l}\text { stride length } \\
\text { (m) }\end{array}$ & 0.088 & 0.0046 & 0.046 & 0.0054 & 0.074 & 0.0037 & 0.035 & 0.0023 \\
\hline $\begin{array}{l}\text { specific COM } \\
\text { amplitude } \\
\text { (L) }\end{array}$ & 0.012 & 0.00057 & 0.012 & 0.00047 & 0.0085 & 0.00089 & & \\
\hline $\begin{array}{l}\text { COM amplitude } \\
\text { (m) }\end{array}$ & 0.0027 & 0.0001 & 0.0021 & 0.0002 & 0.0021 & 0.0002 & & \\
\hline Froude efficiency & 0.81 & 0.011 & 0.78 & 0.034 & 0.82 & 0.013 & 0.82 & 0.017 \\
\hline propeller efficiency & 0.62 & 0.023 & 0.55 & 0.069 & 0.64 & 0.026 & 0.65 & 0.034 \\
\hline Strouhal number & 0.57 & 0.025 & 0.62 & 0.061 & 0.59 & 0.029 & 0.25 & 0.047 \\
\hline
\end{tabular}

COM, center of mass; L, body length; S.E., standard error; und. amplitude, tail tip amplitude for forward swimming or the average amplitude along body for backward swimming. See results for statistical tests between species and travel directions. 
Table 2: The results of the linear regressions of selected kinematic parameters against specific swimming speed.

\begin{tabular}{|c|c|c|c|c|c|c|c|c|c|c|}
\hline & & & $\begin{array}{l}\text { specif. } \\
\text { undul. } \\
\text { ampl. } \\
\text { (L) }\end{array}$ & $\begin{array}{c}\text { wave } \\
\text { frequency } \\
(\mathrm{Hz})\end{array}$ & $\begin{array}{l}\text { specif. } \\
\text { wave } \\
\text { length } \\
(\mathrm{L})\end{array}$ & $\begin{array}{l}\text { specif. } \\
\text { stride } \\
\text { length } \\
\text { (L) }\end{array}$ & $\begin{array}{l}\text { specif. } \\
\text { ampl. } \\
\text { COM } \\
\text { (L) }\end{array}$ & $\begin{array}{c}\text { Froude } \\
\text { eff. }\end{array}$ & $\begin{array}{l}\text { propeller } \\
\text { eff. }\end{array}$ & $\begin{array}{c}\text { Strouhal } \\
\text { number }\end{array}$ \\
\hline \multirow{8}{*}{ P. boro } & \multirow{4}{*}{ forw. } & $\mathrm{a}$ & -0.01 & 1.78 & 0.09 & 0.18 & 0.0035 & 0.10 & 0.20 & -0.30 \\
\hline & & b & 0.11 & 0.54 & 0.57 & 0.26 & 0.01 & 0.74 & 0.48 & 0.78 \\
\hline & & $\mathrm{P}$ & 0.56 & $<0.01 *$ & $<0.01^{*}$ & $<0.01^{*}$ & 0.05 & $0.02 *$ & $0.02 *$ & $<0.01^{*}$ \\
\hline & & $r^{2}$ & 0.02 & 0.82 & 0.39 & 0.48 & 0.18 & 0.25 & 0.25 & 0.46 \\
\hline & \multirow{4}{*}{ backw. } & $\mathrm{a}$ & 6.61E-04 & 1.80 & 0.01 & 0.11 & 0.00087 & 0.11 & 0.22 & -0.10 \\
\hline & & $\mathrm{b}$ & 0.08 & 1.95 & 0.46 & 0.14 & 0.01 & 0.67 & 0.33 & 0.73 \\
\hline & & $\mathrm{P}$ & 0.91 & 0.10 & 0.88 & 0.07 & 0.40 & 0.07 & 0.07 & 0.44 \\
\hline & & $r^{2}$ & $<0.01$ & 0.65 & 0.01 & 0.73 & 0.24 & 0.71 & 0.71 & 0.21 \\
\hline \multirow{8}{*}{ H. hassi } & \multirow{4}{*}{ forw. } & $\mathrm{a}$ & -0.01 & 3.08 & -0.04 & 0.10 & 0.01 & 0.13 & 0.26 & -0.33 \\
\hline & & $\mathrm{b}$ & 0.09 & 0.12 & 0.48 & 0.25 & 0.01 & 0.77 & 0.53 & 0.73 \\
\hline & & $\mathrm{P}$ & 0.70 & $<0.01^{*}$ & 0.67 & 0.32 & 0.29 & 0.10 & 0.10 & $0.05^{*}$ \\
\hline & & $r^{2}$ & 0.03 & 0.89 & 0.03 & 0.16 & 0.18 & 0.38 & 0.38 & 0.50 \\
\hline & \multirow{4}{*}{ backw. } & $\mathrm{a}$ & -0.01 & 6.82 & -0.01 & -0.01 & & 0.01 & 0.02 & -0.13 \\
\hline & & $\mathrm{b}$ & 0.03 & -0.06 & 0.25 & 0.16 & & 0.82 & 0.64 & 0.35 \\
\hline & & $\mathrm{P}$ & $0.03 *$ & $<0.01^{*}$ & 0.36 & 0.88 & & 0.89 & 0.89 & 0.40 \\
\hline & & $r^{2}$ & 0.58 & 0.88 & 0.14 & $<0.01$ & & $<0.01$ & $<0.01$ & 0.12 \\
\hline
\end{tabular}

a, slope; ampl, amplitude; COM, center of mass; b, intercept; backw., backward; eff., efficiency; forw., forward; L, body length; specif, specific; und. ampl., tail tip amplitude for forward swimming or average amplitude along the body for backward swimming. * significant correlations at alpha $=0.05$ 
Herrel et al., Figure 1

\section{Pisodonophis boro}

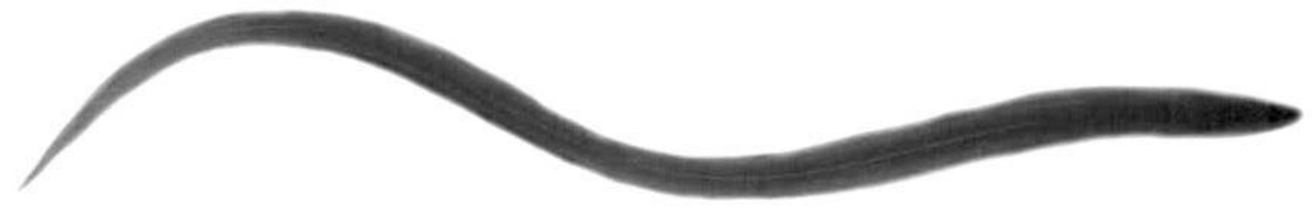

a
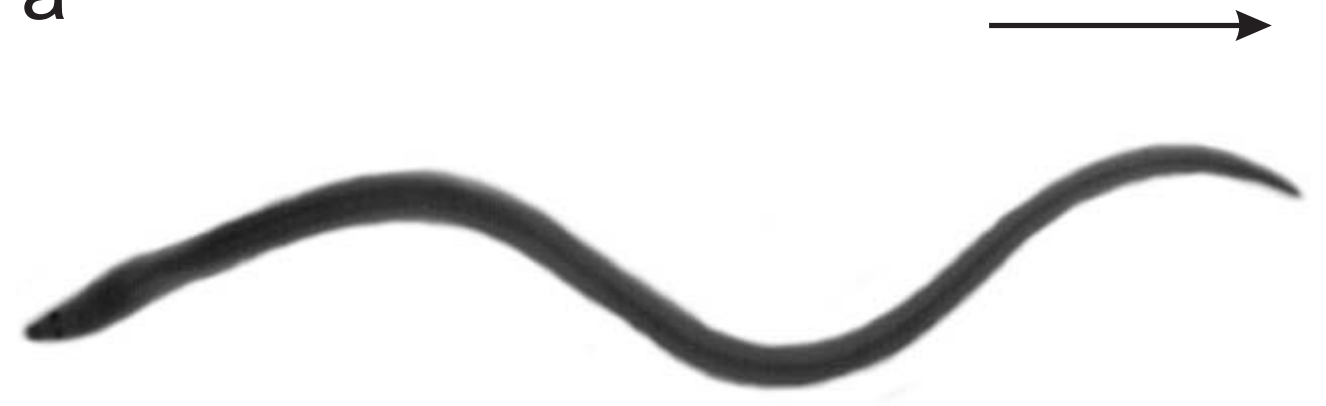

b

Heteroconger hassi

C
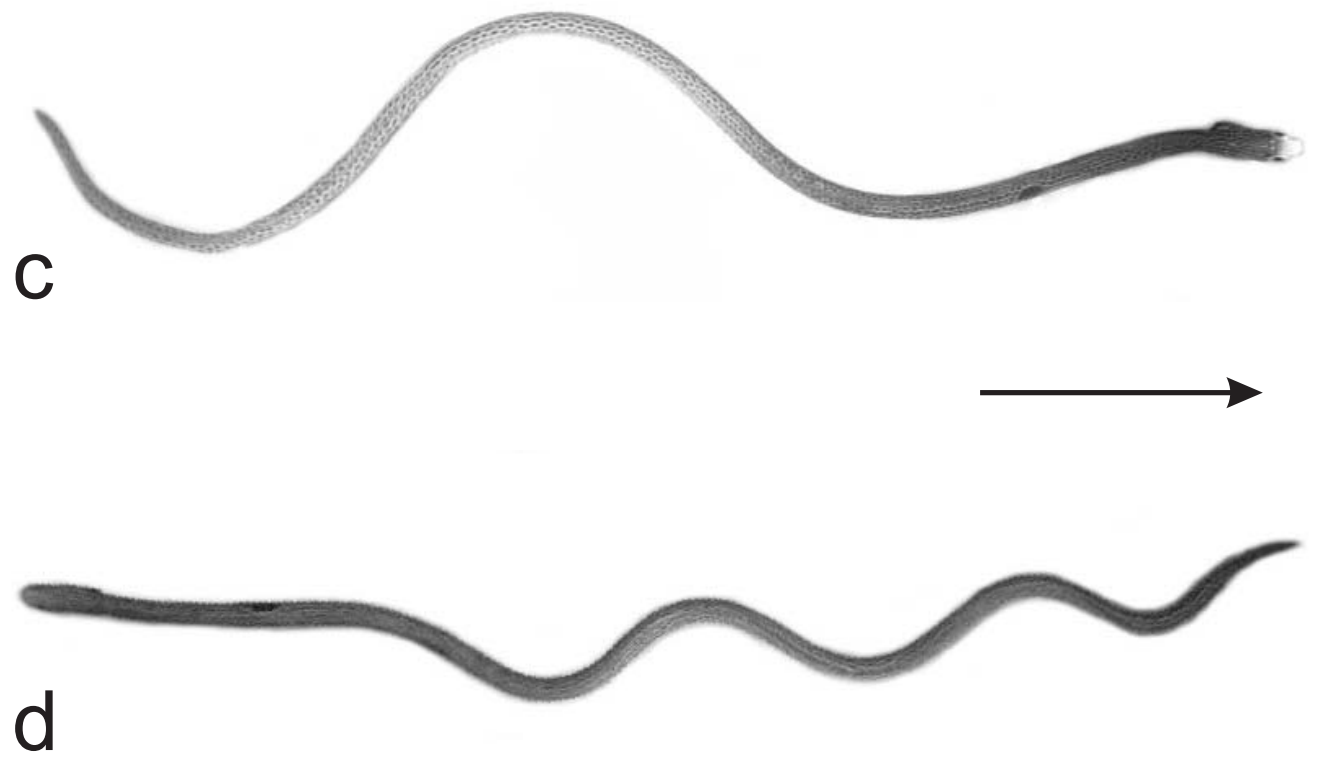
Herrel et al., Figure 2
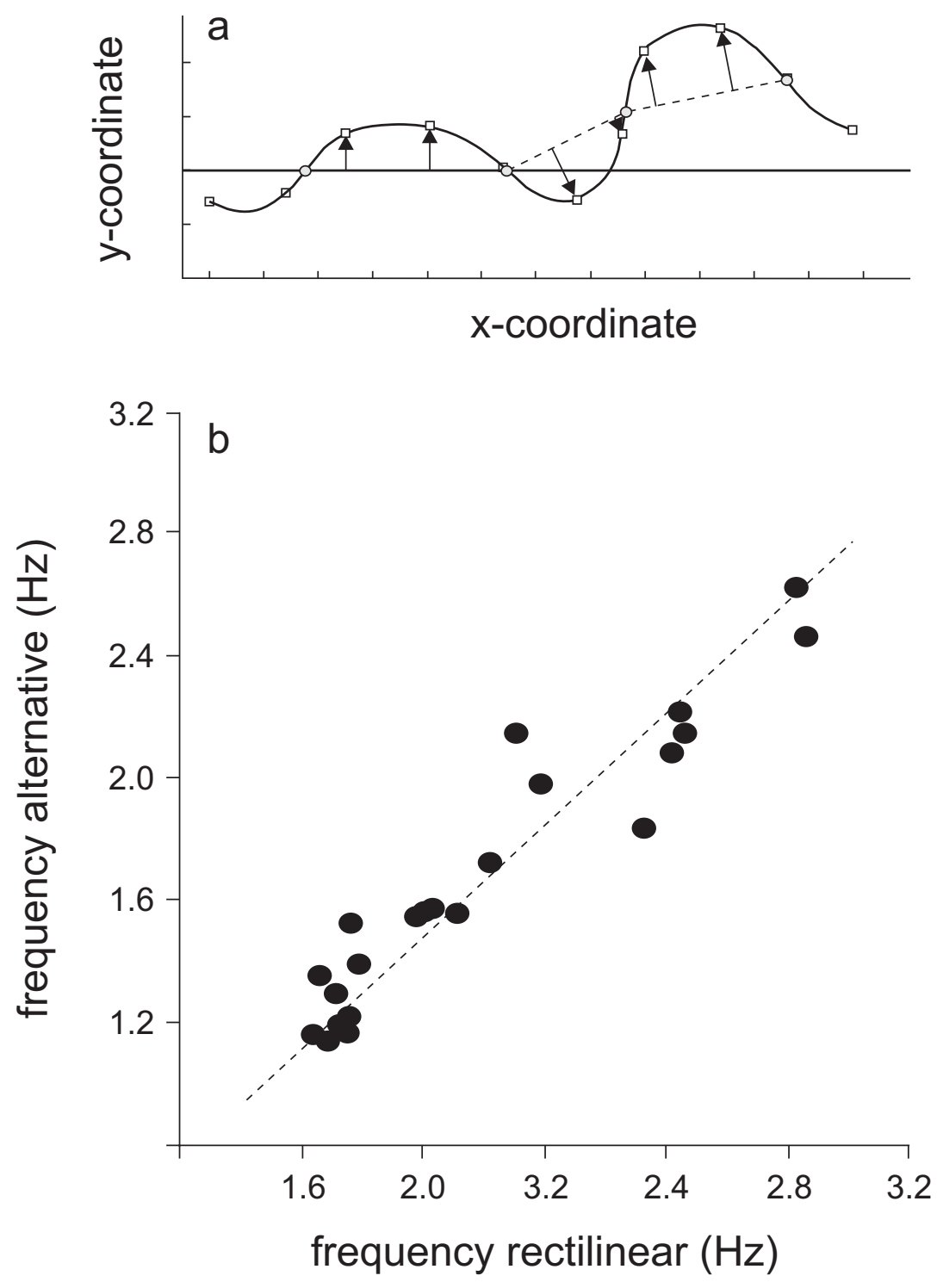
Herrel et al., Figure 3

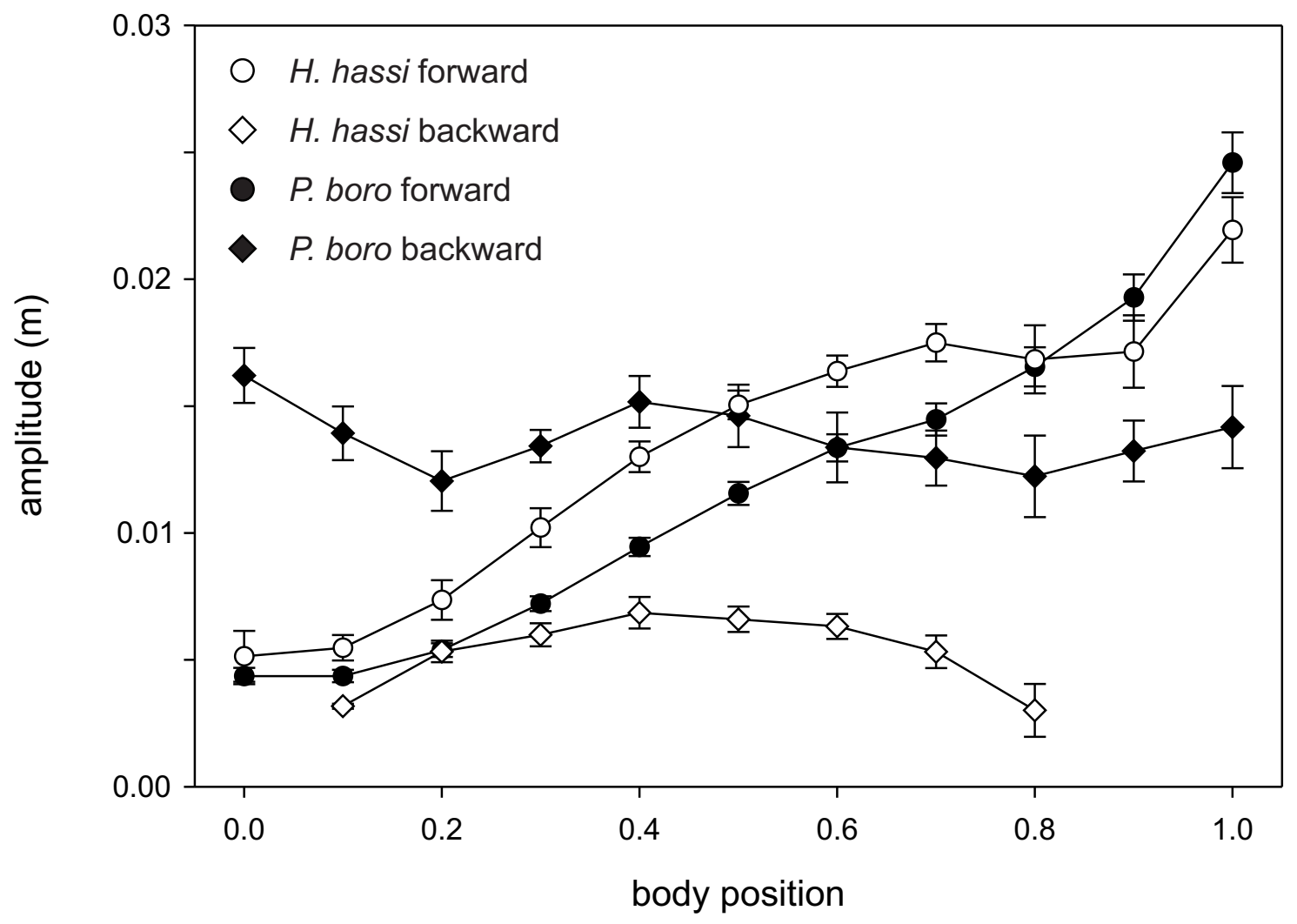


Herrel et al., Figure 4
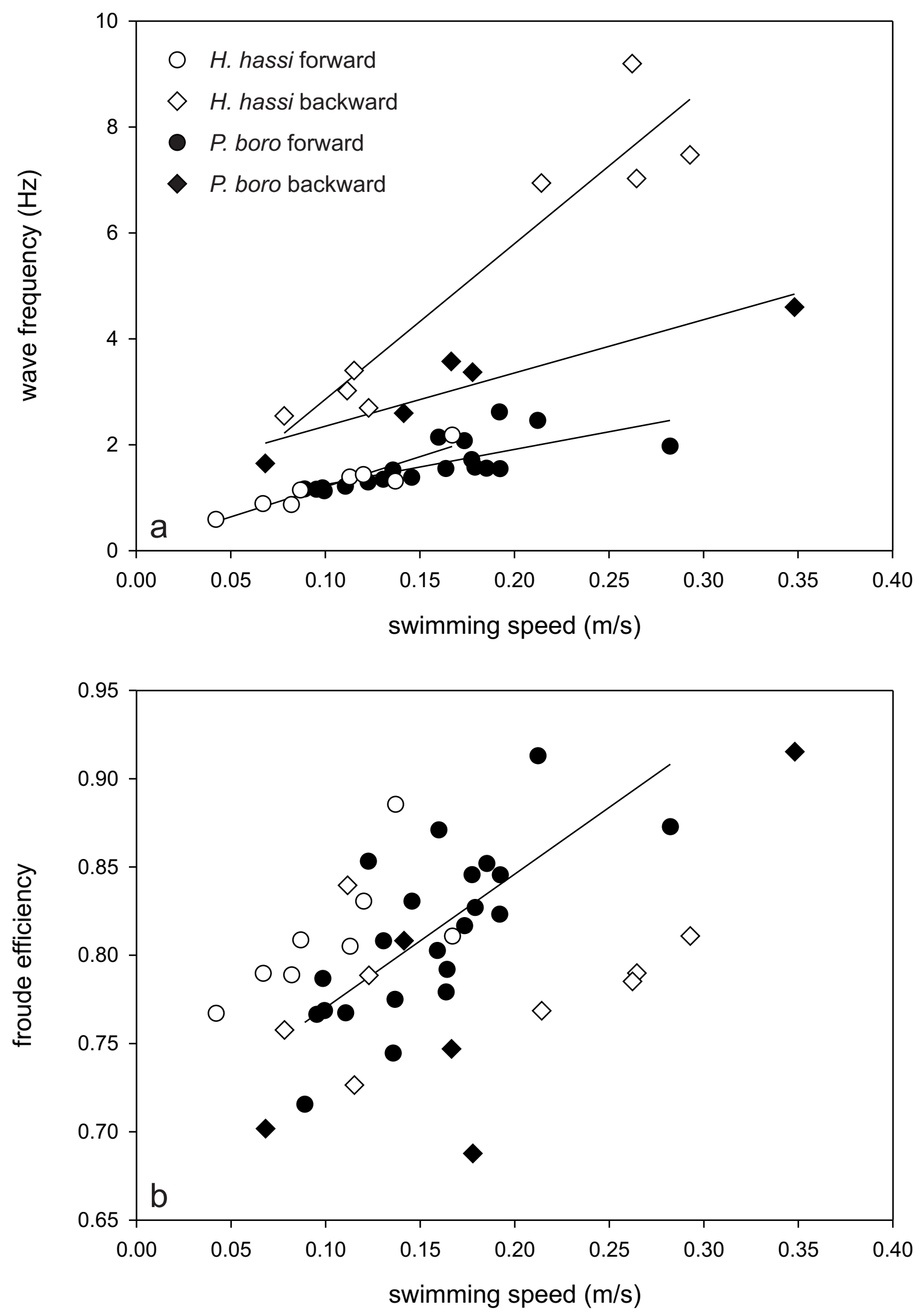